\title{
祁连山北坡中段植物群落多样性的垂直分布格局
}

\author{
王国宏 $^{12}$ \\ 1 (中国科学院植物研究所植被数量生态学开放研究实验室, 北京 100093 ) \\ 2 (甘肃农业大学, 兰州 730070)
}

摘要: 利用 DCCA 排序和海拔高程排序相结合的方法, 对祁连山北坡中段植物群落物种多样性垂直分布格局进行 了初步研究。结果表明 : 1) 植物群落草本层和灌木层物种丰富度和多样性在环境梯度上呈单峰曲线变化趋势, 乔 木层的物种丰富度和多样性在环境梯度上无变化。物种丰富度和多样性对环境梯度变化敏感程度的次序是草本 层 > 灌木层 $>$ 乔木层; 2 ) 植物群落各层次均匀度在环境梯度上没有表现出一定的变化规律, 均匀度可能更多地受 制于群落自身动态的影响, 而独立于生境的资源水平；3) 草地群落物种多样性在 DCCA 环境梯度上曲线的拟合效 果优于按海拔高程排序效果, 灌木群落则相反 ; 4 ) 低海拔、中低海拔和中海拔地带的草本层物种丰富度和 ShannonWiener 多样性指数 $\left(H^{\prime}\right)$ 显著高于灌木层 $(p<0.01)$; 高海拔地带草本层仅丰富度指数显著高于灌木层 $(p<0.05)$ 。 在整个海拔范围内, 草本层和灌木层的均匀度无显著差异。就资源的可利用性而言, 研究区域植物群落物种多样 性在垂直环境梯度上的变化规律表达了物种多样性与资源生产力的单调关系内涵。

关键词: 物种多样性, 海拔梯度, DCCA , 植物群落, 张掖, 祁连山北坡

中图分类号:Q948 文献标识码 : A 文章编号 : 1005-0094(2002)01-0007-08

\section{Species diversity of plant communities along an altitudinal gradient in the middle section of northern slopes of Qilian Mountains , Zhangye , Gansu , China}

WANG Guo-Hong

Laboratory of Quantitative Vegetation Ecology, Institute of Botany, Chinese Academy of Sciences , Beijing 100093

Gansu Agricultural University, Lanzhou 730070

Abstract : Measurements of species diversity of plant communities along both DCCA axis 1 and an altitudinal gradient in the northern slopes of Qilian mountains was carried out. The results showed that : 1) Both species richness and diversity in the herb layer significantly peaked at the intermediate elevations. The same trend was also suggested in the shrub layer, but the curves of both richness and diversity were not significant. Both richness and diversity in the tree layer showed no changes with increased altitude , suggesting that the order of sensitivity in terms of the responses of richness and diversity to altitudinal gradients was herb layer, then shrub layer and tree layer. 2 ) Evenness of the three layers showed no noticeable trend with altitude, suggesting that the dynamics of evenness of a given plant community may be strongly influenced by some fundamental characteristics of plant community rather than resource availability. 3 ) The fitted curve of both diversity and richness of herb layer with DCCA axis 1 was more significant than that fitted with altitudinal gradient, while that of shrub layer showed the opposite trend. 4 ) Of all the comparisons between shrub and herb layer in terms of richness, diversity and evenness, the differentiation was significant for both richness and diversity in the lower altitudinal zone $(p<0.01)$, the mid-lower to mid-altitudinal zone $(p<0.01)$ (excluding Simpson diversity index $(D))$ and in the high altitudinal zone $(p<0.05)$ ( excluding both Shannon-Wiener diversity index $\left(H^{\prime}\right)$ and Simpson diversity in- 
dex). The differentiation of evenness between shrub layer and herb layer was not significant in any of the comparisons. The pattern of species diversity-altitudinal gradient reported here demonstrates a monotonic relationship between productivity and species diversity related to resource availability.

Key words : species diversity, altitudinal gradient, DCCA, plant communities, the northern slopes of Qilian Mountains, Zhangye city

物种多样性的空间分布格局受制于许多生态 梯度的影响（Grime，1979;Palmer,1992;Huston， 1994 ) ,而海拔梯度被认为是影响物种多样性格局 的决定性因素之一（Szaro,1989;DeBano \& Schmidt， 1990 ; Lieberman et al. , 1996 ; Zimmerman et al. 1999 ;Lomolino 2001;Brown ,2001)。尽管几个世纪 以前, 人们已经认识到了物种多样性随海拔梯度变 化的现象，但就这一问题至今尚未形成普遍共识 ( Lomolino 2001)。许多研究表明, 中海拔往往拥有 最大的物种多样性, 如热带雨林 (Lieberman et al. ， 1996 ; Vazquez \& Givnish ,1998 ;Zimmerman et al. , 1999 ) 和小型哺乳动物群落等 ( Heaney,2001 ;Rickart 2001;Md Nor 2001)。但也有许多相反的例证， 即多样性与海拔梯度之间并无特定的关系 (Stevens, 1992 ; Pausas, 1994 ; Rey Benayas, 1995 )。 Lomolino (2001) 认为, 多样性与海拔梯度格局的 关系 (正相关、负相关或单峰关系) 在很大程度上依 赖于环境变量之间的协变与互作。因此, 在对环境 因子全面测度和客观取样的基础上，不同分类群或 不同山区物种多样性的比较研究, 对阐明物种多样 性 - 海拔梯度的关系仍然是至关重要和必须的 (Lomolino 2001;Brown 2001)。

祁连山北坡海拔梯度极其显著, 突出表现为海 拔梯度上水热因子的剧烈变化, 如年均温度变化幅 度 $6^{\circ} \mathrm{C}$ ( alt. $\left.1500 \mathrm{~m}\right) \sim-5.4^{\circ} \mathrm{C}($ alt. $3800 \mathrm{~m})$; 降雨量 幅度 $129.7 \mathrm{~mm}$ (alt. $1500 \mathrm{~m}$ ) 690.26 mm (alt. $3800 \mathrm{~m}$ )。本区植被科学的研究已有了一定的积累 ( 陈庆诚，1966 魏克勤，1990;王国宏等，1995,2001； 王国宏，杨利民，2001），但植物群落物种多样性与 海拔梯度的量化分析尚未见报道。本区丰富的生物 多样性资源是维持山地 - 荒漠 - 绿洲复合生态系统 稳定和持续发展的基础。由于近百年来对资源不合 理的开发利用 (滥圼、滥伐及过度放牧等), 导致诸 如森林面积缩小、草场退化、生物多样性资源丧失的 严重生态后果，对祁连山北坡地区特别是对河西绿 洲的生存与发展构成严重的威胁。开展生物多样性
的基础研究不仅具有重要的理论意义, 而且对揭示 系统退化与修复机制, 制定合理的社会经济发展战 略等也可提供指导和借鉴。本文对祁连山北坡中段 植物群落多样性垂直变化格局的初步研究, 试图揭 示:1) 乔、灌、草不同生活型植物群落物种多样性对 垂直海拔梯度的响应，2) 资源可利用性与物种多样 性格局的关系 3) 海拔梯度上同一群落不同层次多 样性的变化特征。

\section{1 基本概况}

研究区域位于河西走廊中段甘肃省张掖市境 内 地理坐标 $99^{\circ} 31^{\prime} \sim 100^{\circ} 51^{\prime} \mathrm{E}, 38^{\circ} 14^{\prime} \sim 39^{\circ} 14^{\prime} \mathrm{N}$ 。 地貌组合包括祁连山北坡山地及其山前冲积扇荒 漠。在中国气候区划分中, 分别属于高原亚寒带半 干旱区和中温带干旱区。研究区域生态地理的详细 描述见王国宏等(2001)。

\section{2 研究方法}

\section{1 样地调查}

在海拔 $1500 \sim 3700 \mathrm{~m}$ 的范围内, 采用机械取样 法, 海拔每升高 $100 \mathrm{~m}$, 在不同生境( 主要是坡向、坡 位和坡形) 和不同的植物群落中设样地。乔木和灌 木群落取样面积为 $100 \mathrm{~m}^{2}, 4$ 个重复, 每个样地划分 为 4 个 $25 \mathrm{~m}^{2}$ 的木本植物样方和 4 个 $1 \mathrm{~m}^{2}$ 的草本样 方。草地群落样地随机布设 5 个 $1 \mathrm{~m}^{2}$ 的样方。记 录每个物种的高度、多度、盖度; 实测样地海拔高度、 坡向、坡度、坡位、坡形和土壤腐殖质层厚度。样地 年均降雨量数据根据张掖祁连山水源林研究所的不 同海拔气象哨 (站) 气象观测资料 (1984 1995 年) 赋值, 年均温度以寺大隆气象站 (海拔 $2600 \mathrm{~m}$, 年 均温度 $0.6^{\circ} \mathrm{C}$ ) 观测值推算 $\left(0.55^{\circ} \mathrm{C} / 100 \mathrm{~m}\right.$ ) (车克钧 等, 1998)。共调查 92 块临时样地, 记录到乔木树种 4 种, 灌木树种 42 种, 草本植物 176 种, 分别占样区 乔、灌、草物种总数的 $100 \% 、 93 \%$ 和 $47 \%$ 。

\section{2 数据处理}

建立样方、物种和环境变量的数据库。物种变 
量信息以重要值表达 $(I V=$ 相对多度 + 相对盖度 + 相对高度)。环境变量定性指标予以数量化 (坡向 北坡 4 ,西北(南)坡 3 ,东北(南)坡 2 ,南坡 1 坡位 上 1 ,中 2 ,下 3 地形: 谷地 1 ,坡地 2 ,山脊 3 )。多 样性测度:丰富度指数为样地中出现的物种数 $S$;多 样性指数为 Simpson 指数 $(D)$ 和 Shannon-Wiener 指 数 $\left(H^{\prime}\right)$;均匀度指数为 Pielou 均匀度指数 $\left(J_{s w}\right)$ 和 Gini 均匀度指数 $\left(J_{g i}\right)$ 。具体数学公式为：

$\left.D=1-\sum\left[N_{i}\left(N_{i}-1\right)\right] / N(N-1)\right] ; H^{\prime}=$ $-\sum P_{i} \log P_{i} ; J_{s w}=\left(-\sum P_{i} \log P_{i}\right) / \log S ; J_{g i}=(1-$ $\left.\sum P_{i}^{2}\right) /(1-1 / S)$ (Whittaker, 1972)。

式中 $S$ 代表样地或层次中的物种总数; $N$ 代表样地 或层次的总重要值; $N_{i}$ 是第 $i$ 个物种的重要值; $P_{i}$ 为第 $i$ 个物种的相对重要值 $P_{i}=N_{i} / N$ 。

对灌木样方和草地样方进行了去势典范对应分 析 (DCCA) , 并对二者测度指数分别进行了海拔高 程和 DCCA 第一排序轴之间的回归分析。

\section{3 结果分析}

\section{1 排序轴与环境变量的关系}

从 DCCA 排序结果看 (表 1) ,草本层前 4 个排 序轴特征值占总特征值的 $66.79 \%$ (第一、二、三、四 排序轴的信息百分比分别是 $21.32 \% 、 18.08 \% 、 15$. $58 \%$ 和 $11.81 \%$ ），灌木层前 4 个排序轴特征值占总 特征值的 $79.94 \%$ (第一、二、三、四排序轴的信息百 分比分别是 $34.16 \% 、 22.38 \% 、 14.69 \%$ 和 $8.71 \%$ ), 说明排序效果良好。草地群落排序中, 各环境因子 与 DCCA 第一轴均存在着极为显著的相关关系; 灌
木群落排序中, 除坡形和土壤腐殖质因子外, 其他环 境因子与 DCCA 第一轴同样存在极显著的相关关 系。同时, 草地群落和灌木群落 DCCA 第一轴均具 有最高的特征值和最大的梯度长度 (排序轴信息量 的一个测度指标, 表示梯度的变化幅度)。这说明, DCCA 第一轴代表样区内一个重要的环境梯度, 它 所代表的生态意义也是清晰的。对草地群落而言， 沿 DCCA 第一轴自左向右, 随着海拔升高, 降雨量逐 渐增加, 平均温度逐渐降低, 山体变得陡峭, 土壤腐 殖质逐渐增加。灌木群落 DCCA 第一轴代表的环境 梯度与草地群落相似 (坡形和土壤腐殖质对灌木群 落物种多样性空间分布格局的影响可能较小)。因 此，样方在 DCCA 第一轴的排序位置代表了样方在 环境空间中的生态位, 通过各样方群落物种多样性 的比较, 可能会较客观地反映出多样性与环境梯度 之间的内在联系。

\section{2 植物群落多样性在垂直环境梯度上的变化格 局}

3.2.1 丰富度、多样性和均匀度 如图 1 所示, 无 论样方按海拔高程直接排序还是按照 DCCA 第一轴 环境梯度排序, 灌木层样地间丰富度指数在海拔梯 度上总体表现出单峰曲线变化趋势, 但是曲线拟合 不显著 $(p>0.05)$ 。草本层丰富度指数在环境梯度 上的变化趋势呈显著的单峰曲线变化 $(p<0.001)$ (图 2 ) 利用多项式拟合效果优于灌木层。由于祁 连山北坡中段乔木层物种较少, 特定群落乔木层往 往只有 1 种植物, 因此, 乔木层海拔梯度上丰富度和 多样性没有明显变化。由此推论, 具有不同生

表 1 DCCA 排序各环境因子与前 4 个排序轴相关系数及各排序轴的特征值和梯度长度

Table 1 Correlations of environmental variables with the first four axes of DCCA as well as their eigenvalues and lengths of gradient

\begin{tabular}{|c|c|c|c|c|c|c|c|c|}
\hline \multirow{2}{*}{ 环境因子 Environmental factor } & \multicolumn{4}{|c|}{ 草地群落 Grassland } & \multicolumn{4}{|c|}{ 灌木群落 Shrubland } \\
\hline & AX1 & AX2 & AX3 & AX4 & AX1 & $\mathrm{AX} 2$ & AX3 & AX4 \\
\hline 海拔 Altitude & $0.580^{* *}$ & -0.139 & $-0.338^{*}$ & 0.101 & $0.771^{* *}$ & -0.091 & -0.082 & 0.115 \\
\hline 坡向 Slope aspect & $0.632^{* *}$ & $-0.322^{*}$ & 0.018 & 0.188 & $0.602^{* *}$ & -0.238 & 0.234 & -0.129 \\
\hline 坡度 Slope angle & $0.610^{* *}$ & -0.199 & -0.262 & 0.067 & $0.438^{*}$ & -0.036 & $-0.494^{*}$ & 0.036 \\
\hline 坡形 Topography & $0.664^{* *}$ & -0.292 & 0.014 & 0.014 & 0.118 & 0.017 & -0.339 & 0.05 \\
\hline 年均降雨 Annual mean precipitation & $0.578^{* *}$ & -0.139 & $-0.313^{*}$ & 0.087 & $0.728^{* *}$ & -0.098 & -0.08 & 0.06 \\
\hline 土壤腐殖质 Humus of soil & $0.546^{* *}$ & -0.299 & 0.070 & 0.148 & 0.277 & -0.094 & 0.22 & -0.209 \\
\hline 特征值 Eigenvalues & 0.972 & 0.825 & 0.711 & 0.539 & 0.911 & 0.597 & 0.392 & 0.218 \\
\hline 梯度长度 Lengths of gradient & 16.088 & 7.747 & 8.534 & 5.411 & 7.68 & 4. 207 & 2.974 & 2.36 \\
\hline
\end{tabular}




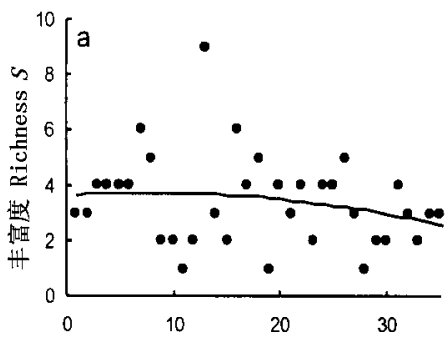

样方DCCA排序 Plots with DCCA axis1

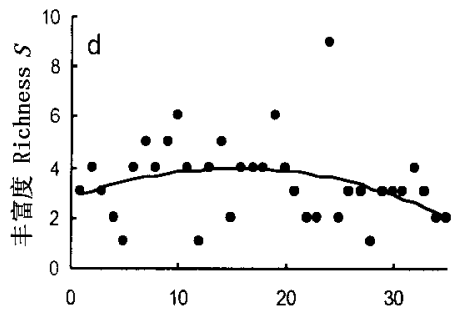

样方的海拔梯度排序 Plots with altitudinal gradient

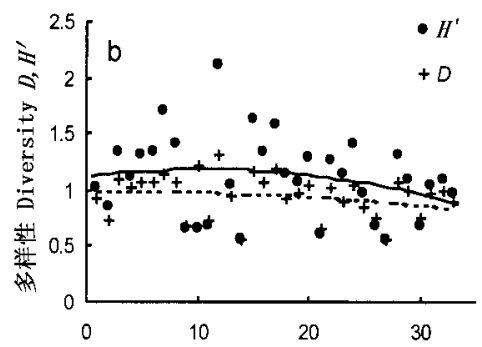

样方DCCA排序 P1ots with DCCA axis1

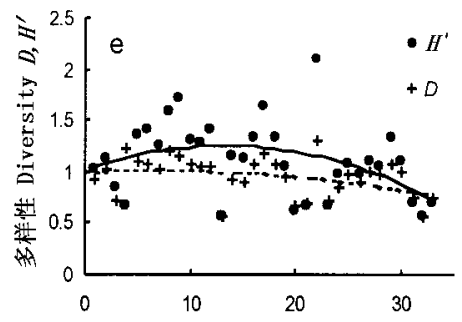

样方的海拔梯度排序 Plots with altitudinal gradient

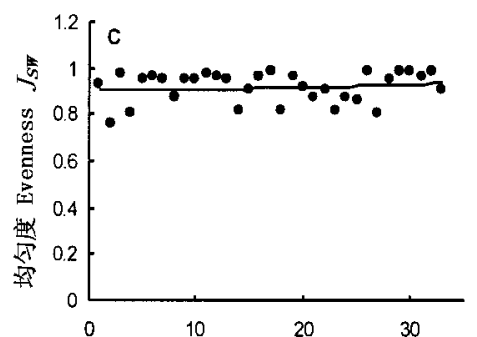

样方DCCA排序 Plots with DCCA axis1

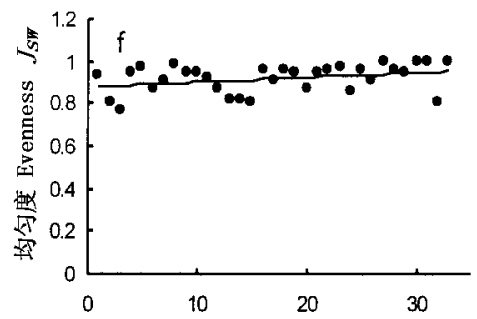

样方的海拔梯度排序

Plots with altitudinal gradient

图 1 灌木群落丰富度、多样性和均匀度在 DCCA 第一轴排序梯度和海拔梯度上的变化趋势

Fig. 1 Patterns of richness, diversity and evenness of shrublands varying with both DCCA axis 1 and altitudinal gradient 拟合方程 Regression equation :

(1) DCCA 排序 Plots ranked with DCCA axis 1 :

$\mathrm{a}:$ 丰富度 Richness index is the number of species $S$, fitted curve is $y=-0.0016 x^{2}+0.256 x+3.6277, R^{2}=0.0558, n=34, p$ $>0.05 ; \mathrm{b}:$ 多样性 Shannon-Wiener index ,fitted curve is $y=-0.0006 x^{2}+0.0125 x+1.1184, R^{2}=0.056, n=34, p>0.05$, fitted curve for Simpson index is $y=-0.0002 x^{2}+0.0024 x+0.9834, R^{2}=0.0534, n=34, p>0.05 ; \mathrm{c}:$ 均匀度 Evenness is Pielou index , fitted curve is $y=4 \mathrm{E}-05 x^{2}-0.0003 x+0.908, R^{2}=0.0196, n=34, p>0.05$.

(2) 海拔高程排序 Plots ranked with altitudinal gradient :

$\mathrm{d}:$ 丰富度 Richness index $S$, fitted curve is $y=-0.0051 x^{2}+0.1566 x+2.7568, R^{2}=0.0534, n=34, p>0.05 ; \mathrm{e}:$ 多样性 Shannon-Wiener index, fitted curve is $y=-0.0014 x^{2}+0.036 x+1.0139, R^{2}=0.1694, n=34, p>0.05$; Simpson index , fitted curve is $y=-0.0004 x^{2}+0.0053 x+0.9971, R^{2}=0.1528, n=34, p>0.05 ; \mathrm{f}$ : 均匀度 Fitted curve of Pielou index of evenness is $y=-4 \mathrm{E}-06 x^{2}-0.0024 x+0.877, R^{2}=0.1076, n=34, p>0.05$.

活型外貌的植物群落对环境梯度变化响应的敏感程 度不同。样区植物群落物种丰富度对环境变化的敏 感程度由大到小的次序是草本层 > 灌木层 > 乔木 层。

如图 1 所示,样方按海拔高度排序和 DCCA 排 序, 多样性表现出较一致的结果。灌木层样地间多 样性指数在垂直环境梯度上波动十分剧烈，总体上 同样表现出一个单峰曲线变化趋势 $(p>0.05)$ 。草 本层多样性指数波动十分剧烈,在环境梯度上的变 化趋势呈显著的单峰曲线变化 $(p<0.01)$ (图 2 ) , 利 用多项式拟合效果优于灌木层。显然,在环境梯度 上, 植物群落物种多样性对环境变化的敏感程度和 丰富度表现出相似的趋势, 各层次物种多样性对环 境变化敏感程度的序列也是草本层 $>$ 灌木层 $>$ 乔木 层。草本层和灌木层均匀度指数在海拔梯度和 DC$\mathrm{CA}$ 环境梯度上虽有波动，但总体却没有明显的变化
趋势。说明环境梯度变化对植物群落均匀度没有明 显的影响 $(p>0.05)$ 。

上述植物群落丰富度、多样性和均匀度的变化 还原为具体的海拔范围, 其变化趋势为: 草本层在海 拔 $2400 \sim 2950 \mathrm{~m}$ 的中海拔地带丰富度和多样性最 高。中海拔地带草本层物种丰富度和 Shannon-Wiener 多样性指数均显著高于高海拔和低海拔相应层 次的指数 $(p<0.01)$ ( 表 2 )。灌木层中海拔物种多 样性和丰富度除与低海拔 $(1500 \sim 2000 \mathrm{~m})$ 有显著 差异外 $(p<0.01)$,与中低海拔 $(2000 \sim 2400 \mathrm{~m})$ 和 高海拔 (2950 3700 m) 均无显著差异。不同海拔 带间灌木层和草本层均匀度指数无显著差异。此 外, 不同海拔草本层和灌木层物种丰富度和多样性 差异显著性检验与曲线的多项式拟合结果反映的趋 势一致, 即草本层物种丰富度和多样性对海拔梯度 变化的敏感程度大于灌木层。 


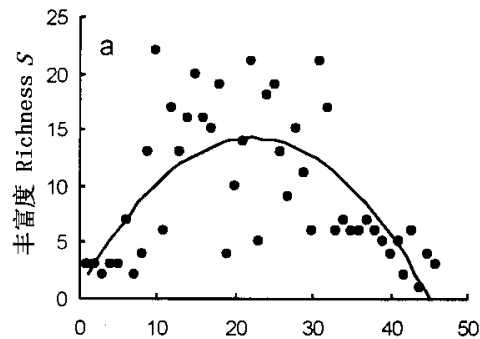

样方DCCA排序 Plots with DCCA axis1

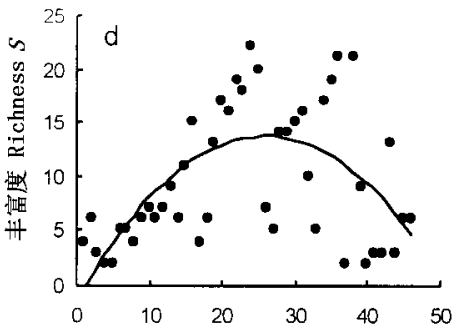

样方的海拔梯度排序

Plots with altitudinal gradient

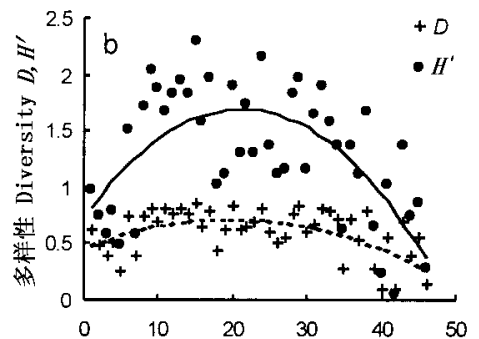

样方DCCA排序 Plots with DCCA axis1

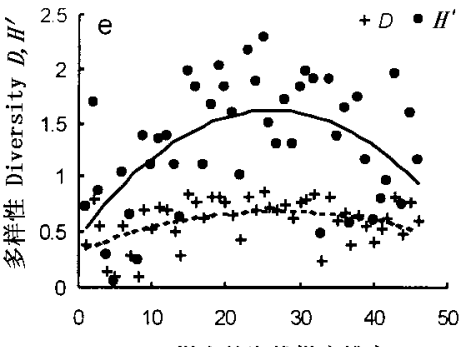

样方的海拔梯度排序

Plots with altitudinal gradient

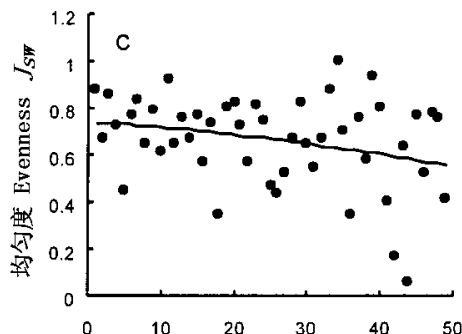

样方DCCA排序 Plots with DCCA axis

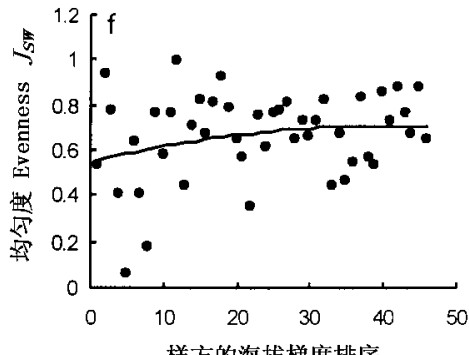

Plots with altitudinal gradient

图 2 草地群落丰富度、多样性和均匀度在 DCCA 第一轴排序梯度和海拔梯度上的变化趋势

Fig. 2 Patterns of richness, diversity and evenness of grassland varying with DCCA axis1 and altitudinal gradient 拟合方程 Regression equation:

(1) DCCA 排序 Plots ranked with DCCA axis 1:

a : 丰富度 Richness index is the number of species $S$, fitted curve is $y=-0.029 x^{2}+1.1933 x+1.0145, R^{2}=0.4716, n=46$ ， $p<0.001 ; \mathrm{b}$ : 多样性 Shannon-Wiener index , fitted curve is $y=-0.0022 x^{2}+0.0911 x+0.7294, R^{2}=0.4258, n=46, p<0.01$; fitted curve for Simpson index is $y=-0.0007 x^{2}+0.0269 x+0.4535, R^{2}=0.3301, n=46, p<0.05 ; \mathrm{c}$ : 均匀度 Evenness is Pielou index , fitted curve is $y=1 \mathrm{E}-05 x^{2}-0.0002 x+0.7399, R^{2}=0.0796, n=46, p>0.05$.

(2) 海拔高程排序 Plots ranked with altitude :

$\mathrm{d}$ : 丰富度 Richness index $S$, fitted curve is $y=-0.0225 x^{2}+1.1653 x+1.3509, R^{2}=0.3782, n=46, p<0.01 ; \mathrm{e}:$ 多样性 Shannon-Wiener index , fitted curve is $y=-0.0017 x^{2}+0.089 x+0.4488, R^{2}=0.2782, n=46, p>0.05$;Simpson index, fitted curve is $y=-0.0005 x^{2}+0.0266 x+0.2387, R^{2}=0.2035, n=46, p>0.05 ; \mathrm{f}$ : 均匀度 Fitted curve of Pielou index of evenness is $y=-1 \mathrm{E}-04 x^{2}-0.008 x+0.546, R^{2}=0.0604, n=46, p>0.05$.

表 2 同一海拔范围不同层次的群落和不同海拔范围同一层次的群落丰富度、多样性和均匀度指数差异显著性检验 $(\mathbf{t}-$ 检 验

Table 2 Significance test on the differentiation of the indices of diversity, richness and evenness in the different layers of plant communities of an altitudinal range as well as the different altitudinal ranges of a layer in the northern slopes of Qilian Mountains

L Shrub

L-M Herb

L-M Shrub

M Herb

M Shrub

H Herb

H Shrub
L Herb

* *

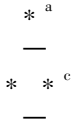

NS
L Shrub

L-M Herb

L-M Shrub

M Herb

M Shrub

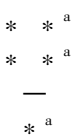

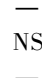

$*^{a}$

* *
NS ${ }^{\mathrm{b}}$

注 Notes：L Shrub：低海拔灌木层 Shrub layer in low elevations (1500 2000 m) ; L Herb : 低海拔草本层 Herb layer in low elevations (1500 2000 m) ; L-M Shrub : 中低海拔灌木层 Shrub layer in low to mid elevations (2000 2400 m) ; L-M Herb : 中低海拔草本层 Herb layer in low to mid elevations $(2000 \sim 2400 \mathrm{~m})$; M Shrub : 中海拔灌木层 Shrub layer in mid elevations $(2400 \sim 2950 \mathrm{~m})$; M Herb : 中海拔草本层 Herb layer in mid elevations $(2400 \sim 2950 \mathrm{~m})$; H Shrub : 高海拔灌木层 Shrub layer in high elevations $(2950 \sim 3700 \mathrm{~m})$; H Herb : 高海拔草本层 Herb layer in high elevations $(2950 \sim 3700 \mathrm{~m})$ 。

**: $: \mathrm{t}$-检验,$p<0.01$ ( $\mathrm{t}$-test,$p<0.01) ; *: \mathrm{t}$-检验,$p<0.05$ ( $\mathrm{t}$-test,$p<0.05) ;-$ : 没有比较二者差异 No comparison was made ; NS : 差异 不显著 Difference is not significant ; a : Simpson 指数 $(D)$ 不显著 Significance is not for Simpson diversity index ; b : 丰富度指数 $(S)$ 显著，Simpson 指数 $(D)$ 和 Shannon-Wiener 指数 $\left(H^{\prime}\right)$ 均不显著 Significance is only for $S$ richness index ; c : Simpson 指数的显著水平是 $p<0.05$ Simpson diversity index is significant at $p<0.05$. Pielou 均匀度指数 $\left(J_{s w}\right)$ 和 Gini 均匀度指数 $\left(J_{g i}\right)$ 在所有的检验中均无显著差异 Pielou index of evenness and Gini index of evenness are not significant at $p<0.05$ in all tests involved 

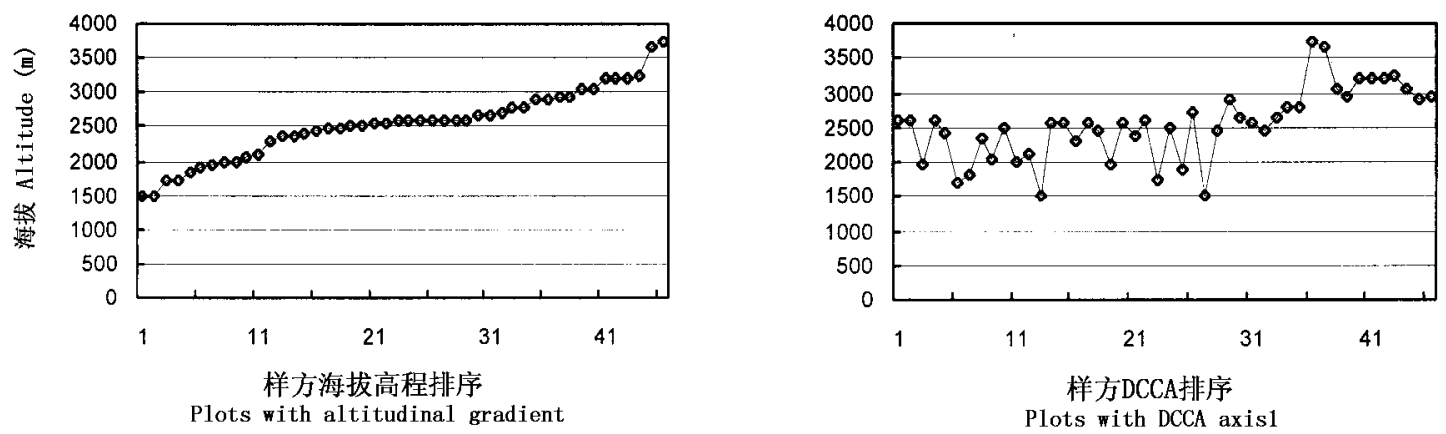

图 3 草地群落样方 DCCA 第一轴排列后样地海拔高程的变化

Fig. 3 Changes of altitude of plots in grasslands after re-ranked according to their score on DCCA axis1

\subsubsection{DCCA 排序与海拔排序的关系 海拔梯度} 主要反映水热梯度变化( Marrs et al. ,1988;Kitayama ,1992;Pendry \& Proctor ,1996)。样方按海拔高 程排序, 只能反映出与海拔变化密切相关的环境因 子的空间特征。祁连山北坡山体陡峭, 地形变化复 杂，同一等高线上随着地形、坡向的变化，不同空间 水热水平迥然不同。以海拔高程排序样方,并不能 真实地反映样地所处的资源生产力水平 [资源生产 力指能量流过生态系统的速率 (Abrams ,1995) , 本 文指特定生境各种环境因子的综合特征]。相反， DCCA 第一轴是所涉及的各种环境因子所构成的一 个综合排序梯度，以 DCCA 对样方进行排序可能较 客观地反映样方的环境资源生产力水平。比较 DCCA 排序前后样方海拔高程变化 (图 3 ) ,DCCA 梯度 上各样方间海拔高程虽然也表现出由低到高的变化 趋势，但样方间海拔高程的波动十分剧烈，说明 DC$\mathrm{CA}$ 排序对样方海拔梯度序列的改造是强烈的。从 灌木层和草本层丰富度、多样性分别以 DCCA 排序 和海拔梯度排序后的变化趋势看，二者表现出较大 的同一性，但 DCCA 所形成的曲线峰值偏左，海拔梯 度曲线峰值偏右。从曲线方程拟合看, 草本层各指 数 DCCA 排序的变化曲线拟合效果优于海拔梯度排 序后拟合效果, 而灌木层则相反。说明灌木群落的 物种多样性动态可能更多地受制于大尺度海拔梯度 所代表的水热变化, 而草本层主要受制于小尺度资 源可利用性影响。

3.3 同一海拔范围植物群落不同层次的多样性比 较

祁连山北坡海拔范围依据主要植被类型划分为 4 个海拔带, 即低海拔 (1500 2000 m) , 中低海拔
$(2000 \sim 2400 \mathrm{~m})$, 中海拔 (2400 2950 m) 和高海拔 (2950 3700 m) (王国宏等 2001)。

由于乔木层丰富度和多样性最低, 而均匀度指 数最高, 因此, 我们没有把乔木层纳入比较的范围， 仅对同一海拔范围灌木层和草本层丰富度、多样性 和均匀度进行了比较。结果表明 (图 4 , 表 2 ), 低海 拔地带草本层丰富度指数和多样性指数均显著高于 灌木层 $(p<0.01)$; 中低海拔和中海拔地带草本层 物种丰富度和 Shannon-Wiener 多样性指数 $\left(H^{\prime}\right)$ 也显著高于灌木层 $(p<0.01)$, Simpson 多样性指数 $(D)$ 在草本层和灌木层的差异没有达到显著水平。 高海拔地带草本层和灌木层仅丰富度指数差异达到 显著水平 $(p<0.05)$,Shannon-Wiener 多样性指数 $\left(H^{\prime}\right)$ 和 Simpson 多样性指数 $(D)$ 的差异均不显著。 此外, 在所有的比较中, 草本层和灌木层的均匀度指 数均无显著差异。

\section{4 讨论}

在群落物种多样性的空间分布格局中, 物种多 样性随海拔梯度变化一直是生态学家感兴趣的论 题。从本文的测度结果看, 祁连山北坡植物群落物 种多样性的垂直分布规律在植物群落不同的层次得 到了不同的表达。草本层的变化趋势最明显, 即在 中海拔地带物种丰富度和多样性达到最高; 灌木层 次之, 多样性和丰富度在中海拔地带最高, 但变化趋 势不明显; 在乔木层的海拔分布范围内, 其物种多样 性对海拔梯度没有响应。这说明, 物种多样性的海 拔分布格局不仅在不同的区域其变化格局不同, 而 且同一地区植物群落不同层次对海拔梯度变化的响 应也存在差异。此外, 通过对样方的海拔高程直接 排序和DCCA第一轴梯度排序的比较，我们发现，二 

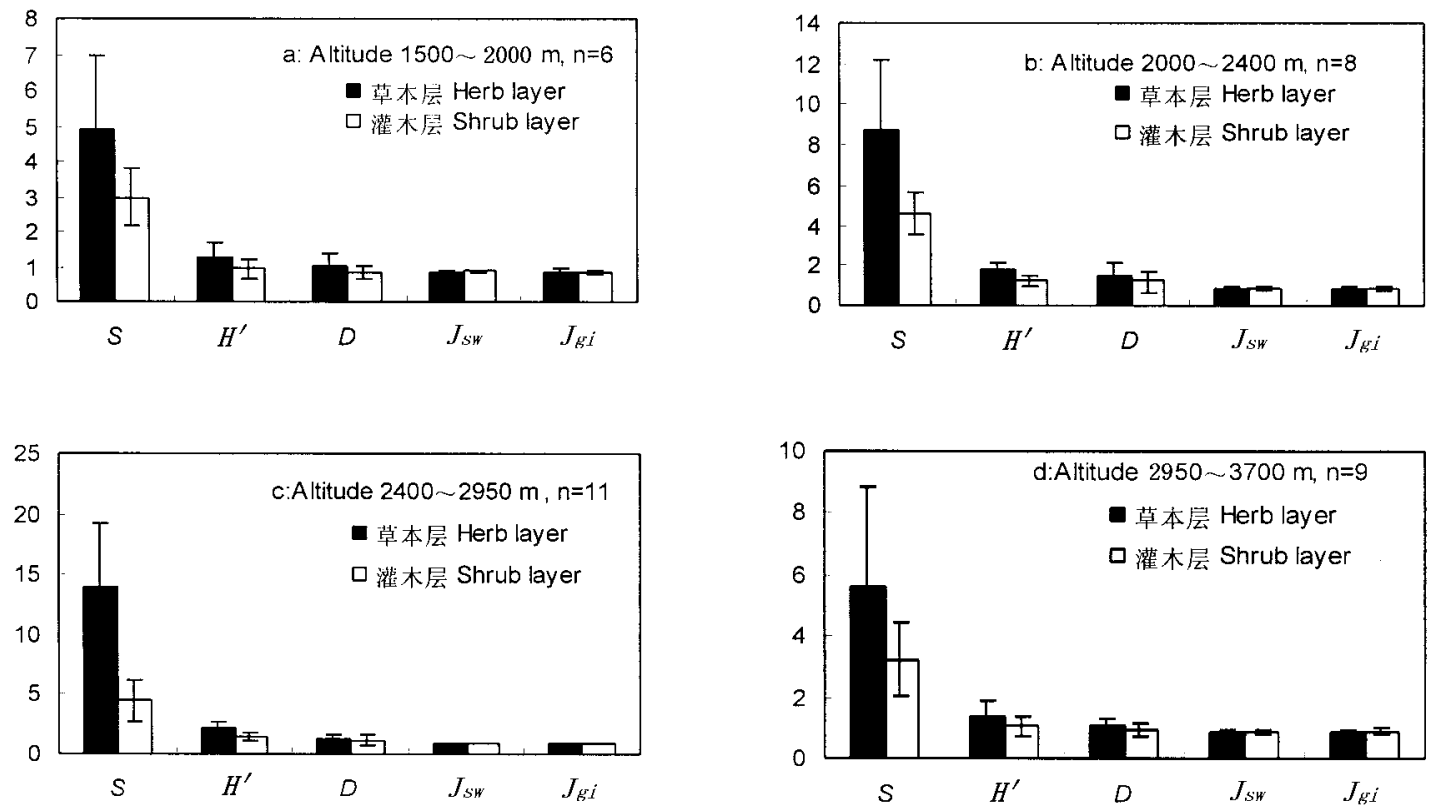

图 4 不同海拔范围内植物群落草本层和灌木层的丰富度、多样性和均匀度的比较

Fig. 4 Comparisons of species diversity between shrub layer and herb layer of a given plant community in different altitudinal ranges 图中植物群落各层次指数用均值 \pm 标准误表示。All results plotted are Means \pm SD.

者排序结果所表达的物种多样性的变化趋势有较大 的一致性，说明海拔梯度在一定程度上的确代表着 一个重要的资源生产力的梯度。但是也应该注意 到，其他因子 (如地形因子) 对海拔梯度所框定的水 热梯度进行着再修饰,在地形变化复杂的山地环境 就更是如此。因此, 特定海拔高程处生境的海拔梯 度效应很可能因为地形等微环境的变化而得到削弱 或加强。祁连山北坡山体陡峭地形变化复杂,同一 等高线上因地形、坡向的不同，直接影响了水热因子 的分布。从这一点上讲, 海拔梯度并不能完全代表 资源生产力梯度。特定海拔处各环境因子综合作用 所形成的综合资源量可能是决定群落多样性动态的 根本因素。DCCA 排序是环境梯度分析的一个强有 力的工具。在物种多样性的空间分布格局研究中， 尽可能全面地收集样地的环境变量数据, 对样方进 行梯度分析，然后分析环境梯度上群落物种多样性 的变化, 所得出的结论可能更具客观性。就本文研 究结果看，样方按照 DCCA 排序后，物种多样性在样 地间仍存在剧烈的波动，说明群落的物种多样性除 受资源水平的影响外，还受其他因素的深刻影响，如 群落的发育阶段、外界干扰、生物之间的互作等。

群落的物种多样性与环境的资源水平 (资源生 产力)之间存在着密切的关系,二者之间的格局主 要有单调关系和单峰关系两种学说。单调关系指群
落中随着资源生产力的增加, 群落物种多样性亦增 加或随着资源生产力的降低物种丰富度也随之下降 (Abrams,1995)。单峰关系学说认为, 在生产力较 低时, 多样性随生产力的增加而增加, 但当生产力达 到足够高时多样性会下降, 亦即在群落生产力达到 中等水平时出现最高的多样性 (Abrams,1995)。本 文中, 如果资源生产力以水分梯度或热量梯度衡量， 则草地群落物种多样性与资源生产力的关系是单峰 关系, 因为物种多样性水平较高的中海拔或中等环 境梯度地带的水分和热量均不是最高。同时应该注 意到, 在低海拔地带, 植物生长季节热量充足, 水分 不足; 高海拔地带, 水分充足热量不足。显然, 在环 境梯度两极, 对植物生长发育起至关重要的水分和 热量因子是相互抑制的。相反, 在中海拔地带, 尽管 水分和热量的绝对量不是最高, 但水热组合最佳, 资 源的可利用性可能是最高的。可见, 就资源的可利 用性而言, 祁连山北坡草地植物群落物种多样性在 垂直生态梯度上的变化规律表达了物种多样性与资 源生产力的单调关系内涵。Bastow et al. (1999) 指 出, 在小尺度上均匀度随着样方面积的增加而增大, 均匀度的这种变化趋势可能是对微环境异质性的响 应。但在大的尺度上,均匀度无明显的变化趋势 (黄建辉,1997) 。本文结论与后者相类似, 无论样 方按海拔高程直接排序还是 DCCA 排序,均匀度并 
没有随着环境梯度的变化表现出特定的变化规律。 这说明植物群落均匀度的特征更多地受制于群落自 身特征的影响,而独立于特定生境的资源生产力水 平。

在同一海拔范围内群落不同层次 (灌木层和草 本层)物种多样性和丰富度的比较中, 草本层的丰 富度和多样性均高于灌木层, 该结论与温带森林群 落不同层次物种多样性的测度结果一致( 黄建辉, 1997 )。同时我们注意到，地带性森林群落同一群 落不同层次物种多样性的比较研究中，不同层次物 种丰富度和多样性的格局与大尺度地带性气候表现 出相关变化趋势（黄建辉，1997），这说明特定植物 群落不同层次多样性格局可能是对区域宏观气候特 征的直接响应。与物种丰富度和多样性在不同层次 间明显的变化趋势不同，均匀度在同一群落不同的 层次间并无显著差异, 其中的机理尚待进一步研究。

\section{5 结论}

祁连山北坡植物群落物种多样性在海拔梯度上 的分布格局表明:不同生活型植物群落物种多样性 对海拔梯度响应的敏感程度不同, 草本植物群落最 敏感, 其次是灌木群落和乔木群落;物种多样性与特 定环境因子 ( 如降雨量或温度) 梯度之间呈单峰关 系, 最大的物种多样性出现在中海拔地带; 油于中海 拔地带资源组合最优化，就资源的可利用性而言，物 种多样性的海拔梯度分布格局表达了多样性 - 资源 生产力之间的单调关系内涵。

致谢:感谢导师任继周院士、胡自治教授对本文的指 导。

\section{参考文献}

车克钧, 傅辉恩, 王金叶, 1998. 祁连山水源林生态系统结构 与功能的研究. 林业科学, 34(5):29 37

陈庆诚, 1966. 甘肃省祁连山一些高山植物形态 - 生态学特 征的观察. 植物生态学与地植物学资料丛刊, 4:39 64

黄建辉, 高贤明, 马克平, 陈灵芝, 1997. 地带性森林群落物 种多样性的比较研究. 生态学报, 17(6): 611 618

王国宏, 车克钧, 王金叶, 1995。祁连山北坡植物区系研究. 甘肃农业大学学报, 30(3): 249 255

王国宏, 任继周, 张自和, 2001。河西山地绿洲荒漠植物群落 种群多样性研究 I. 生态地理及植物群落的基本特征. 草业学报, 10(1)：1 11

王国宏,杨利民, 2001。祁连山北坡中段森林植被梯度分析 及环境解释. 植物生态学报, 25(6):752 759

魏克勤, 1990. 祁连山水源涵养林区的青海云杉林. 兰州大学 学报文集, 26:2 8

Abrams P A, 1995. Monotonic or unimodal diversity-productivity gradients: what does competition theory predict? Ecolo$g y, \mathbf{7 6}(7): 2019 \sim 2027$

Brown J H, 2001. Mammals on mountainsides: elevational pat- terns of diversity. Global Ecology \& Biogeography, 10: 101 $\sim 109$

Bastow W J, B S John, K WarrenMcG and G Habiba, 1999. The effect of spatial scale on evenness. Journal of Vegetation Science, 10: $463 \sim 468$

DeBano L F and L J Schmidt, 1990. Potential for enhancing riparian habitats in the southwest United States with watershed practices. Forest Ecology and Management, 33: 385 $\sim 403$

Grime J P, 1979. Plant strategies and Vegetation Processes. Chichester, Wiley

Heaney L R, 2001. Small mammal diversity along elevational gradients in the Philippines: an assessment of patterns and hypotheses. Global Ecology and Biogeography, 10: $15 \sim 39$

Huston M A, 1994. Biological Diversity: the Coexistence of Species on Changing Landscapes. Cambridge University Press, New York

Kitayama K, 1992. An altitudinal transect study of the vegetation on Mount Kinabalu, Borneo. Vegetatio, 102: 149 171

Lieberman D, M Lieberman, R Peralta and G Hartshorn, 1996. Tropical forest structure and composition on a large-scale altitudinal gradient in Costa Rica. Journal of Ecology, 84: $137 \sim 152$

Lomolino M V, 2001. Elevation gradients of species-density: historical and prospective views. Global Ecology \& Biogeography, 10: $3 \sim 13$

Marrs R H, J Proctor, A Heaney and M D Mountfied, 1988. Changes in soils, nitrogen mineralization and nitrification along an altitudinal transect in tropical rain forest in Costa Rica. Journal of Ecology, 76: $466 \sim 482$

Md Nor S, 2001. Elevational diversity patterns of small mammals on Mount Kinabalu, Sabaha, Malaysia. Global Ecology \& Biogeography, 10:41 62

Palmer M W, 1992. The coexistence of species in fractal landscapes. American Naturalist, 139: $375 \sim 397$

Pausas J G, 1994. Species richness patterns in the understorey of Pyrenean Pinus sylvestris forest. Journal of Vegetation Science, 5: $517 \sim 524$

Pendry C A and J Proctor, 1996. The causes of altitudinal zonation of rain forests on Bukit Belalong, Brunei. Journal of $E$ cology, 84: $407 \sim 418$

Rey Benayas J M, 1995. Patterns of diversity in the strata of boreal forest in British Columbia. Journal of Vegetation Science, 6: $95 \sim 98$

Rickart E A, 2001. Elevational diversity gradients, biogeography, and the structure of montane mammal communities in the intermountain region of North America. Global Ecology \& Biogeography, 10: $77 \sim 100$

Stevens G C, 1992. The elevational gradient in altitudinal range: an extension of Rapoport's latitudinal rule to altitude. American Naturalist, 140: $893 \sim 911$

Szaro R C, 1989. Riparian forest and scrubland community types of Aricona and New Mexico. Desert Plants, 9:69 138

Vazquez G J A and T J Givnish, 1998. Altitudinal gradient in tropical forest composition, structure, and diversity in the Sierra de Manantlan. Journal of Ecology, 86: $999 \sim 1020$

Whittaker R H, 1972. Evolution of measurement of species diversity. Taxon, 21: $213 \sim 251$

Zimmerman J C, L E DeWald and P G Rowlands, 1999. Vegetation diversity in an interconnected ephemeral riparian system of north-central Arizona, USA. Biological Conservation, 90: $217 \sim 228$ (责任编辑 : 间文杰) 